\title{
Political business cycles and inflation stabilization
}

\author{
Vítor Castro $^{\mathrm{a}}$, Francisco José Veiga ${ }^{\mathrm{b}, *}$ \\ ${ }^{\text {a } U n i v e r s i d a d e ~ d e ~ C o i m b r a, ~ C o i m b r a, ~ P o r t u g a l ~}$ \\ ${ }^{\mathrm{b}}$ NIPE-Escola de Economia e Gestão, Universidade do Minho, Gab. 2.04, P-4710-057 Braga, Portugal
}

Received 22 April 2003; accepted 28 July 2003

\begin{abstract}
This article analyzes the effects of the timing of elections on the timing and character of adopted inflation stabilization plans. Multinomial logit estimations show that before elections exchange rate-based stabilizations are more likely to be implemented than money-based stabilizations, while the opposite is more likely after elections. (C) 2004 Elsevier B.V. All rights reserved.
\end{abstract}

Keywords: Inflation stabilization; Nominal anchors; Political business cycles; Elections

JEL classification: E31; E63

\section{Introduction}

Contrary to the conventional wisdom that inflation stabilization has short-run contractionary effects, empirical studies focusing on chronic inflation countries have shown that exchange ratebased stabilization plans (ERBS) often lead to an initial expansion in economic activity, particularly in output and consumption, with recession occurring later on. The short-run recessionary effects typically associated with disinflation occur more quickly following money-based stabilizations (MBS). Thus, according to Calvo and Végh (1999); Kiguel and Leviatan (1992), the choice of the nominal anchor might be interpreted as a choice between recession now and recession later.

\footnotetext{
* Corresponding author. Tel.: +351-2-5360-4534; fax: +351-2-5367-6375.

E-mail address: fjveiga@eeg.uminho.pt (F.J. Veiga).
} 
When the decision regarding the anchor and timing of stabilization is included in models of political business cycles, there is room for political opportunism of policymakers. Following on the work of Rogoff and Sibert (1988), Stein and Streb (1998) have developed a political model of policymaking in which voters reward politicians for perceived competence. In their model, inflation reduction with low output costs signals competence of the government. Thus, the absence of short-run costs of higher unemployment and lower growth provide strong incentives for policymakers to reduce inflation shortly before elections by implementing ERBS.

The hypothesis that the timing and the choice of the nominal anchor of a stabilization might be affected by the timing of elections will be tested via the estimation of a multinomial logit model for a sample of 35 stabilization programs implemented in chronic inflation countries since the late 1950s. The potential effects of economic conditions on the adoption of stabilization plans will also be considered. This approach builds upon and improves upon the work of Aisen (2002), who uses a probit model to estimate the effects of several variables on the probability of implementing an ERBS versus an MBS, assuming that the decision to stabilize has already been made. First, an opportunistic policymaker will not commit to a stabilization program before knowing whether an ERBS or an MBS are preferable to not stabilizing. Thus, the timing and anchor of stabilization should be decided at the same time. Second, Veiga (2000) has shown that the timing of inflation stabilization programs is affected by political variables like the degree of fragmentation of the political system. It is quite possible that it is also affected by the timing of elections. By allowing the policymaker the option of not stabilizing, our model has the advantage of also estimating the effects of the timing of elections and of several economic variables on the timing of stabilizations.

\section{The data and the econometric model}

The dataset is composed of quarterly data from 1957 to 1999 , for 10 countries that experienced chronic inflation and implemented stabilization programs during this period. In order to determine when a stabilization program has been implemented, we searched the economics literature for information on the starting dates of stabilization programs undertaken in countries suffering from chronic inflation. The 44 stabilizations identified are described in Table 1, where the quarter of implementation, the type and the importance of each program are indicated. Those classified as major programs are the ones that received greatest attention in the economics literature.

Since we are interested in testing whether the electoral cycle affects the choice of the nominal anchor and the timing of stabilization, only the programs whose implementation was preceded and followed by elections are included in the sample. Thus, periods in which the political regime was not democratic are excluded. These stabilizations are indicated in bold in the text of the table. Because it makes more sense to test for the probability of implementing a stabilization program when it is clearly necessary, we decided to examine only periods in which inflation was "high". Following Veiga (2000), inflation was considered high when it was over twice the average inflation rate of the last 10 years (and above $25 \%$ ) or greater than or equal to $100 \%$.

We assumed that, in a situation of high inflation, the policymaker could do one of the following: (1) start an ERBS; (2) start an MBS; or postpone the necessary stabilization program (NS, no stabilization). 
Table 1

Stabilization programs

\begin{tabular}{|c|c|c|c|}
\hline Country & Program dates/names & Type & Major program \\
\hline \multirow[t]{14}{*}{ Argentina } & 1958:4 & MBS & \\
\hline & 1959:3 & ERBS & Yes \\
\hline & $1967: 1$ & ERBS & Yes \\
\hline & 1973:3 & ERBS & Yes \\
\hline & 1976:2 & MBS & \\
\hline & 1978:4 (Tablita) & ERBS & Yes \\
\hline & 1985:2 (Austral I) & ERBS & Yes \\
\hline & 1986:3 (Primavera I) & ERBS & \\
\hline & 1987:1 (February) & ERBS & \\
\hline & 1987:4 (Austral II) & ERBS & \\
\hline & 1988:3 (Primavera II) & ERBS & \\
\hline & 1989:3 (BB) & ERBS & \\
\hline & 1989:4 (Bonex) & MBS & Yes \\
\hline & 1991:2 (Convertibility) & ERBS & Yes \\
\hline \multirow[t]{4}{*}{ Bolivia } & 1982:4 & ERBS & \\
\hline & 1984:2 & ERBS & \\
\hline & 1985:1 & ERBS & \\
\hline & 1985:3 & ERBS & Yes \\
\hline \multirow[t]{7}{*}{ Brazil } & 1964:1 & ERBS & Yes \\
\hline & 1986:1 (Cruzado) & ERBS & Yes \\
\hline & 1987:2 (Bresser) & ERBS & \\
\hline & 1988:2 (Gradualist) & ERBS & \\
\hline & 1989:1 (Summer) & ERBS & \\
\hline & 1990:1 (Collor) & MBS & Yes \\
\hline & 1994:3 (Real) & ERBS & Yes \\
\hline \multirow[t]{2}{*}{ Chile } & $1975: 2$ & MBS & Yes \\
\hline & 1978:1 (Tablita) & ERBS & Yes \\
\hline Dominican Republic & 1990:3 & MBS & Yes \\
\hline \multirow[t]{7}{*}{ Israel } & 1980:4 (Aridor I) & ERBS & \\
\hline & 1982:3 (Aridor II) & ERBS & \\
\hline & 1983:4 (Cohen-Orgad) & ERBS & \\
\hline & 1984:3 (Package Deal I) & ERBS & \\
\hline & 1984:4 (Package Deal II) & ERBS & \\
\hline & 1985:1 (Package Deal III) & ERBS & \\
\hline & 1985:3 (Shekel) & ERBS & Yes \\
\hline \multirow[t]{2}{*}{ Mexico } & 1976:4 & ERBS & \\
\hline & 1987:4 & ERBS & Yes \\
\hline \multirow[t]{2}{*}{ Peru } & 1985:3 & ERBS & \\
\hline & 1990:3 & MBS & Yes \\
\hline \multirow[t]{4}{*}{ Uruguay } & 1960:4 & MBS & Yes \\
\hline & 1968:2 & ERBS & Yes \\
\hline & 1978:4 (Tablita) & ERBS & Yes \\
\hline & 1990:4 & ERBS & Yes \\
\hline Turkey & 1980:1 & MBS & Yes \\
\hline
\end{tabular}

Notes: ERBS, exchange rate-based stabilization; MBS, money-based stabilization. The programs whose date/name appears in bold were implemented during election cycles. The others were implemented during dictatorships or followed by dictatorships. Main sources: Bruno et al. (1988); Bruno et al. (1991); Calvo and Végh (1999); Kiguel and Leviatan (1992). See Table 1 of Castro and Veiga (2002) for the specific source used to classify each program. 
Table 2

Description of the variables used

Dependent variable:

$\mathrm{STAB}=0$ if NS program is implemented in the current quarter,

$=1$ if an MBS is implemented, and

$=2$ if an ERBS is implemented.

Independent variables

PCR, number of quarters since the last elections divided by the number of quarters to the next elections (presidential elections are considered in presidential systems, while legislative elections are considered in parliamentary systems).

TR/Imp, ratio of total reserves to imports.

$\Delta \operatorname{Inf}$, change in inflation: $\Delta \operatorname{Inf}=\ln (\operatorname{Inf})-\ln (\operatorname{Inf}(-1))$

Inf, inflation: growth of CPI since the same quarter of the previous year.

GDP $>$ T $=1$ if the growth of real GDP since the same quarter of the previous year is greater than the Trend (Hodrick-Prescott) growth rate of GDP.

FB/GDP, fiscal balance (government budget balance) as a percentage of GDP.

$\mathrm{IMFProg}=1$ if there is an ongoing IMF program (arrangement), and $=0$ otherwise.

Sources: Dependent variable: see Table 1. Independent variables: Arthur Banks, ed., Political Handbook of the World, several issues; World Europa Yearbook, Europa, several issues; International Financial Statistics, IMF. Quarterly data on Real GDP was also obtained from IBGE (Brazil) and INEGI (Mexico). Data on the timing of IMF arrangements was obtained from the IMF Annual Report (several issues) and on the IMF web page (http://www.imf.org).

Since there are three alternatives, the econometric model chosen was the Multinomial Logit ${ }^{1}$. The dependent variable and the independent variables are described in Table 2.

\section{Empirical results}

Table 3 presents the results of the multinomial logit estimations for the contrasts MBS versus NS, ERBS versus NS, and MBS versus ERBS, for all and major programs. Most economic variables are lagged one period in order to avoid simultaneity problems and to account for the usual delays in the reporting of economic data. For each estimated coefficient, the factor change in the odds ${ }^{2}$ and the $t$ statistics are also provided.

The political cycle ratio (PCR) (quarters since the last election divided by quarters before the next election), is statistically significant for the first and last contrasts in both specifications, indicating that the probability of adopting an MBS decreases (relative to NS and to ERBS) as elections come closer ${ }^{3}$. These results clearly support our hypothesis and are consistent with the opportunistic behavior of policymakers described in Stein and Streb's (1998) model. PCR is not statistically significant for the contrast ERBS/NS, indicating that the timing of elections may not affect the decision to adopt an ERBS versus not stabilizing. In fact, there is greater dispersion of ERBS along the election cycle than that of MBS. When the choice concerns the nominal anchor of stabilization, as expected, the probability of adopting an MBS versus an ERBS is greater when PCR is smaller (shortly after elections).

1 For a description of this model see Long (1997).

2 The factor change in the odds (also called odds ratio) represents generically the expected change in the odds of outcome $m$ versus outcome $n$ for a unit change in the variable $X_{k}$, and is equal to $\exp \left(\beta_{k, m \mid n}\right)$.

3 In terms of odds ratios, we can see that for the contrast MBS/ERBS, in the specification for all programs, a unit change in PCR leads to an expected change of the odds by a factor of 0.0427 , ceteris paribus. 
Table 3

Timing and choice of the nominal anchor of stabilization programs

\begin{tabular}{|c|c|c|c|c|c|c|}
\hline & \multicolumn{3}{|l|}{ All programs } & \multicolumn{3}{|c|}{ Major programs } \\
\hline & MBS/NS & ERBS/NS & MBS/ERBS & $\mathrm{MBS} / \mathrm{NS}$ & ERBS/NS & MBS/ERBS \\
\hline \multirow[t]{3}{*}{ PCR } & -3.22945 & -0.076848 & -3.15260 & -3.97782 & -0.062806 & -3.91501 \\
\hline & {$[0.0396]$} & {$[0.9260]$} & {$[0.0427]$} & {$[0.0187]$} & {$[0.9391]$} & [0.0199] \\
\hline & $(-3.33)^{* * *}$ & $(-1.27)$ & $(-3.25)^{* * *}$ & $(-2.92) * * *$ & $(-0.72)$ & $(-2.87)^{* * *}$ \\
\hline \multirow[t]{3}{*}{$\mathrm{TR} / \operatorname{Imp}(-1)$} & -1.55898 & 0.459502 & -2.01848 & -0.961667 & 0.394075 & -1.35574 \\
\hline & {$[0.2104]$} & {$[1.5833]$} & {$[0.1329]$} & {$[0.3823]$} & {$[1.4830]$} & {$[0.2578]$} \\
\hline & $(-2.36)^{* *}$ & $(1.92)^{*}$ & $(-2.93)^{* * *}$ & $(-2.57)^{* *}$ & $(0.93)$ & $(-2.54)^{* *}$ \\
\hline \multirow[t]{3}{*}{$\Delta \operatorname{Inf}(-1)$} & 3.52144 & 0.050426 & 3.47101 & 3.05818 & -1.93714 & 4.99532 \\
\hline & [33.833] & {$[1.0517]$} & [32.169] & [21.289] & {$[0.1441]$} & {$[147.72]$} \\
\hline & $(1.89)^{*}$ & $(0.05)$ & $(1.65)^{*}$ & $(1.77)^{*}$ & $(-1.74)^{*}$ & $(2.45)^{* *}$ \\
\hline \multirow[t]{3}{*}{$\mathrm{GDP}>\mathrm{T}(-1)$} & 1.86371 & -0.447610 & 2.31132 & 1.61842 & 0.038071 & 1.58035 \\
\hline & {$[6.4476]$} & {$[0.6392]$} & {$[10.088]$} & {$[5.0451]$} & {$[1.0395]$} & {$[4.8567]$} \\
\hline & $(1.68)^{*}$ & $(-0.98)$ & $(1.99)^{* *}$ & $(1.38)$ & $(0.06)$ & $(1.21)$ \\
\hline \multirow[t]{3}{*}{$\mathrm{FB} / \mathrm{GDP}(-1)$} & -0.003578 & -0.147799 & 0.144221 & 0.072903 & -0.017556 & 0.090460 \\
\hline & {$[0.9964]$} & {$[0.8626]$} & {$[1.1551]$} & {$[1.0756]$} & {$[0.9826]$} & [1.0947] \\
\hline & $(-0.04)$ & $(-4.18)^{* * *}$ & $(1.43)$ & $(0.62)$ & $(-0.33)$ & $(0.70)$ \\
\hline \multirow[t]{3}{*}{ IMFProg } & 0.981458 & -0.509541 & 1.49100 & 0.373354 & 0.802040 & -0.428687 \\
\hline & {$[2.6683]$} & {$[0.6008]$} & [4.4415] & {$[1.4526]$} & {$[2.2301]$} & {$[0.6514]$} \\
\hline & -1.07 & $(-0.96)$ & $(1.45)$ & $(0.39)$ & $(0.98)$ & $(-0.35)$ \\
\hline Log Likelihood & -82.9907 & & & -52.8209 & & \\
\hline Schwarz B.I.C. & 119.341 & & & 90.3170 & & \\
\hline McFadden $R^{2}$ & 0.2074 & & & 0.1712 & & \\
\hline Number of observations & 180 & & & 212 & & \\
\hline Number of MBS & 6 & & & 5 & & \\
\hline Number of ERBS & 29 & & & 10 & & \\
\hline
\end{tabular}

Sources: see Tables 1 and 2. Notes, the factor change in the odds are in brackets; $t$-statistics are in parentheses; significance level at which the null hypothesis is rejected: ***, $1 \%$; **, 5\%; and *, 10\%; models estimated with a constant, by maximum likelihood (ML). MBS, money-based stabilization; ERBS, exchange rate-based stabilization; NS, no stabilization.

A greater stock of reserves (TR/Imp) reduces the probability of choosing an MBS relative to an ERBS or to not stabilizing. In the results for all programs it also increases the probability of implementing an ERBS relative to not stabilizing. As inflation accelerates $(\Delta \mathrm{Inf})$ the probability of implementing an MBS versus an ERBS or not stabilizing increases. GDP growth above the trend growth rate (GDP $>$ T) increases the probability of adopting an MBS instead of an ERBS or not stabilizing when we use the sample of all 35 programs. In the specification for the 15 major programs, this variable is never statistically significant. These results concerning GDP contradict Gould (1999), who argued that growth above trend would favor the adoption of an ERBS versus an MBS. The fiscal balance as a percentage of GDP (FB/GDP) does not seem to affect the choice of the nominal anchor. But, the results for all programs indicate that a greater budget surplus decreases the probability of implementing an ERBS. Finally, the existence of an ongoing IMF program (IMFProg) does not seem to affect the timing or the choice of the nominal anchor of stabilization ${ }^{4}$.

\footnotetext{
4 See Castro and Veiga (2002) for the results of sensitivity analysis to alternative samples and of a series of robustness tests using other explanatory variables. Since these results are very similar to those of Table 3, our conclusions regarding the influence of the political cycle and other variables remain the same.
} 


\section{Conclusions}

There is clear evidence of opportunistic behavior of policymakers regarding the timing of stabilization and the choice of the nominal anchor. An MBS is more likely to be implemented shortly after elections, while the probability of adopting an ERBS is greater shortly before elections. While the results regarding the choice of the nominal anchor confirm those of Aisen (2002), it should be noted that he assumes that the choice happens after the decision to stabilize was taken, which implies that the election cycle does not affect the timing of stabilization. The most evident innovation of this paper is that, by allowing the policymaker to opt among implementing an MBS, an ERBS or not stabilizing, the effects of the timing of elections and of other factors on the timing of each type of stabilization programs are also analyzed. Our results for the contrast MBS/NS clearly show that the timing of an MBS is affected by the electoral cycle. As previously stated, the probability of adopting an MBS versus not stabilizing is greater immediately after elections.

\section{Acknowledgements}

We acknowledge helpful comments from Henry Chappell and Martin Paldam. Francisco Veiga also wishes to express his gratitude for the financial support of the Portuguese Foundation for Science and Technology (FCT) under research grant POCTI/32491/ECO/2000 (partially funded by FEDER).

\section{References}

Aisen, A., 2002. Money-Based vs. Exchange-Rate-Based Stabilization: Is There Space for Political Opportunism? UCLA (SSRN abstract ID 352660).

Bruno, M., Di Tella, G., Dornbusch, R., Fischer, S. (Eds.), 1988. Inflation Stabilization: The Experience of Israel, Argentina, Brazil, Bolivia, and Mexico. MIT Press, Cambridge, MA.

Bruno, M., Fischer, S., Helpman, E., Liviatan, N., Meridor, L. (Eds.), 1991. Lessons of Economic Stabilization and its Aftermath. MIT Press, Cambridge, MA.

Calvo, G.A., Végh, C.A., 1999. Inflation stabilization and BOP crises in developing countries. In: Taylor, J.B., Woodford, M. (Eds.), Handbook of Macroeconomics, vol. 1. Elsevier, Holland, pp. 1531-1614.

Castro, V., Veiga, F.J., 2002. Political Business Cycles and Inflation Stabilization. NIPE Working Paper, WP 9/2002 Universidade do Minho, Portugal (available in pdf format at http://www.eeg.uminho.pt/economia/fjveiga/erbs_mbs.pdf).

Gould, D.M., 1999. Does the Choice of the Nominal Anchor Matter? Economic Research Working Paper 9914. Federal Reserve Bank of Dallas, Dallas, Tx.

Kiguel, M., Leviatan, N., 1992. The business cycle associated with exchange rate-based stabilizations. The World Bank Economic Review 6, 279-305.

Long, J.S., 1997. Regression Models for Categorical and Limited Dependent Variables. Sage Publications, Thousand Oaks, CA, pp. $148-186$.

Rogoff, K., Sibert, A., 1988. Elections and macroeconomic cycles. Review of Economic Studies 55, 1-16.

Stein, E.H., Streb, J.M., 1998. Political stabilization cycles in high-inflation economies. Journal of Development Economics 56, $159-180$.

Veiga, F.J., 2000. Delays of inflation stabilizations. Economics and Politics 12, 275-295. 